\title{
Trends in Hospitalization Expenditures for Acute Exacerbations of COPD in Beijing from 2009 to 2017
}

This article was published in the following Dove Press journal: International Journal of Chronic Obstructive Pulmonary Disease

\author{
Lirong Liang (D) \\ Yunxiao Shang ${ }^{2}$ \\ Wuxiang $\mathrm{Xie}^{3}$ \\ Julie $\mathrm{Shi}^{2}$ \\ Zhaohui Tong ${ }^{4}$ \\ Mohammad S Jalali (iD ${ }^{5}$ \\ 'Department of Clinical Epidemiology \& \\ Tobacco Dependence Treatment \\ Research, Beijing Institute of Respiratory \\ Medicine, Beijing Chaoyang Hospital, \\ Capital Medical University, Beijing, \\ People's Republic of China; ${ }^{2}$ School of \\ Economics, Peking University, Beijing, \\ People's Republic of China; ${ }^{3}$ Peking \\ University Clinical Research Institute, \\ Peking University Health Science Center, \\ Beijing, People's Republic of China; \\ ${ }^{4}$ Department of Respiratory and Critical \\ Care Medicine, Beijing Institute of \\ Respiratory Medicine, Beijing Chaoyang \\ Hospital, Capital Medical University, \\ Beijing, People's Republic of China; ${ }^{5} \mathrm{MGH}$ \\ Institute for Technology Assessment, \\ Harvard Medical School, Boston, \\ MA, USA
}

Correspondence: Julie Shi; Zhaohui Tong Tel +86-10-62750527;

Tel +86-10-85231610

Email jshi@pku.edu.cn;

tongzhaohuicy@sina.com
Background: Chronic obstructive pulmonary disease (COPD) is the cause of substantial economic and social burden. We investigated trends in hospitalizations for acute exacerbation of COPD in Beijing, China, from 2009 to 2017.

Patients and Methods: Investigations were conducted using data from the discharge records of inpatients that were given a primary diagnosis of acute exacerbation of COPD. The dataset was a retrospective review of information collected from electronic medical records and included 315,116 admissions (159,368 patients). Descriptive analyses and multivariate regressions were used to investigate trends in per admission and per capita expenditures, as well as other potential contributing factors.

Results: The mean per admission expenditures increased from 19,760 CNY (\$2893, based on USD/CNY=6.8310) in 2009 to $20,118 \mathrm{CNY}$ (\$2980) in 2017 (a growth rate of $0.11 \%$ ). However, the per capita expenditures increased from 23,716 CNY (\$3472) in 2009 to 31,000 CNY (\$4538) in 2017 (a growth rate of 1.7\%). In terms of per admission expenditures, drug costs accounted for $52.9 \%$ of the total expenditures in 2009 and dropped to $39.4 \%$ in 2017 ( $P$ trend $<0.001)$. The mean length of stay (LOS) decreased from 16.0 days to 13.5 days $(P$ trend $<0.001)$. Age, gender, COPD type, LOS, and hospital level were all associated with per admission and per capita expenditures.

Interpretation: Relatively stable per admission expenditures along with the decline in drug costs and LOS reflect the effectiveness of cost containment on some indicators in China's health care reform. However, the increase in hospitalization expenditures per capita calls for better policies for controlling hospitalizations, especially multiple admissions.

Keywords: hospitalization expenditures, acute exacerbation of chronic obstructive pulmonary disease, trend analysis

\section{Plain Language Summary}

- The cost of hospitalizations for acute exacerbation chronic obstructive pulmonary disease (AECOPD) is an economic burden for countries worldwide. The reasons for the trends of increasing expenditures have not been analyzed collectively.

- After analyzing a large-scale sample of all AECOPD admissions in Beijing, China, the study finds that the mean per admission expenditures increased from $19,760(\$ 2,893)$ in 2009 to $20,118 \mathrm{CNY}(\$ 2,980)$ in 2017 , and the per capita expenditures increased from $23,716 \mathrm{CNY}(\$ 3,472)$ in 2009 to $31,000 \mathrm{CNY}(\$ 4,538)$ in 2017 . The increasing share of the aging population and increasing number of admissions are critical factors causing the increase in hospitalization costs. 
- The annual growth rate of inpatient expenditures per capita for AECOPD patients was $1.7 \% .93 .5 \%$ of this is attributed to the increased number of admissions and only $6.5 \%$ is attributed to increased expenditures per admission.

- The mean length of stay decreased from 16.0 days to 13.5 days. Age, gender, COPD type, length of stay, and hospital level were all associated with medical costs.

\section{Introduction}

Chronic obstructive pulmonary disease (COPD) is one of the leading causes of morbidity, mortality, and escalation of health care costs worldwide. ${ }^{1}$ In China, COPD was the third leading cause of death, with an average of 68 deaths per 100,000 population, in $2017 .^{2}$ The prevalence of spirometry-defined COPD in China has increased rapidly in the past decade. Between 2012-2015, this was especially prevalent among adults ages 40 years and older with an increase of $5.5 \%$ from the 2002-04 survey. ${ }^{3,4}$ Due to continued exposure to COPD risk factors such as smoking, air pollution, and aging of the population, the global burden of COPD is expected to increase even further in the coming years.

Some individuals with COPD experience at least one exacerbation per year, an outcome that is often associated with COPD progression and prognosis, repeated utilization of health care services, impaired quality of life, and mortality. ${ }^{5-7}$ Hospitalization expenditures for acute exacerbations impart a substantial economic burden on individuals and society. Many studies have quantified the direct costs of COPD and analyzed the factors contributing to its expenses. $^{8-17}$ But there is limited research on hospitalization expenditures for AECOPD, especially in China and other developing countries, which bear the greatest burden.

Over the past few decades in China, several policies have been implemented by the government to control the number of hospitalizations due to AECOPD, such as the improvement of clinical guidelines to ensure proper care for patients with COPD. ${ }^{18,19}$ However, the pattern of hospitalization expenditures over time and the determinant factors for patients with AECOPD remain unclear. To address this gap, this study analyzes the hospitalization costs for AECOPD patients in Beijing, China. We investigate the trend of expenditures over an eight-year period and explore the risk factors that affect its changes.

\section{Materials and Methods}

\section{Data}

The data was obtained from a large-scale hospital discharge database maintained by the Beijing Public Health
Information Center (BPHIC). The center is administered by the government, and all the hospitals in Beijing are required to submit information on the first page of a standardized discharge record to its database. Our data set was retrieved from the discharge database. It included all inpatient records for patients with AECOPD who were admitted by secondary or tertiary hospitals in Beijing from January 1, 2009 to December 31, 2017. The data we obtained include patients' demographics, hospital, date of admission, length of stay (LOS), expenditures, and primary discharge diagnosis. Following the literature, ${ }^{20}$ patients who were younger than 18 were excluded from the sample. Early onset COPD may occur if certain conditions or risk factors are present or if severe early-life conditions have limited lung development, but these conditions are rare. It is possible that many younger patients with "COPD" in this sample have alternative diagnoses. In addition, cases were excluded if they had missing data or the overall inpatient expenditures were less than 500 Chinese yuan (CNY). According to these criteria, about $5 \%$ of the observations were excluded from the analysis, and the study included 315,116 admissions (159,368 patients).

The present study was approved by the Research Ethics Board of Beijing Chaoyang Hospital (2018-ke-303). The data was de-identified by the BPHIC before analysis, and patients could not be identified at the individual level. Given the anonymous and mandatory nature of the data, informed consent was neither required nor necessary.

The sample consists of patients with a primary discharge diagnosis of AECOPD (ICD-10 codes: ${ }^{21}$ J40-J44). Patients with secondary or tertiary diagnosis of AECOPD were not included, as it was possible that those patients were in a stable stage of AECOPD and were admitted for treating other comorbidities (hypertension, diabetes, cardiovascular disease, or cerebrovascular disease). Enrolled cases were classified into four types for sub-disease analysis: bronchitis (J40, J41, J40xx01-J40xx03, J41.101, J41.801, J42xx01-J42xx06, J44.801-J44.802), emphysema (J43.002，J43.101，J43.102，J43.201，J43.801，J43.901J43.905), bulla (J43.902, J43.906), and otherwise unclassified COPD (J44.003, J44.101, J44.901- J44.905).

Our analysis focuses on overall inpatient expenditures, including all services, tests, examinations, and medical materials received in the hospital, such as physician charges, medications, and procedures. The categories are classified by the BPHIC according to standardized criteria, and categorized expenditures are provided in the data set. 
The total expenditures contain out-of-pocket amounts and costs reimbursed by health insurance. Two key outcomes are assessed based on calendar year data: (1) expenditures per admission, and (2) annual expenditures per person/ annual expenditures per capita. We believe that the second measure provides a better description of the financial burden for patients with COPD, since many patients experience multiple admissions. All expenditures have been adjusted to 2017 CNY using the annual Consumer Price Index. Since drug costs in China have been a significant point of interest for researchers and policy makers, we broke down annual expenditures into drug and non-drug expenses and examined the trend in the proportion attributed to the drug costs. Drug expenses include all medications given to patients during their hospital stays.

\section{Statistical Analysis}

Descriptive statistics are presented as the mean \pm standard deviation, median, and interquartile range for continuous variables and frequencies for categorical variables. The mean expenditures are calculated per admission and mean annual expenditures for each year. The trends in expenditures are compared by age (18-39, 40-59, 60-69, 70-79, and $\geq 80$ years), gender (male and female), disease type (bronchitis, emphysema, bulla, and COPD), and hospital level (secondary and tertiary). To analyze the time trends for characteristics of admissions, poisson regression is used for admission numbers, logistic regression for gender and hospital level, multinomial logit regression for age and disease type, the Kruskal-Wallis test for LOS, and linear regression for the share of drug costs. Multivariable linear regression analysis is conducted to determine contributing factors and examine how they vary between per admission and per capita expenditures, controlling for all other determinants. Statistical analysis is performed using Stata 14.0. Statistical significance is set at $<0.05$ for a two-tailed test.

\section{Results}

The characteristics of inpatients with AECOPD from 2009 to 2017 are shown in Table 1. Admissions for AECOPD increased from 2009 to 2014 and proceeded to decline in subsequent years. The majority of the patients were male, and the proportion of males increased over the study period $(58.8 \%$ in 2009 and $68.8 \%$ in $2017, P$ trend < $0.001)$. Majority were also over 70 years of age, and the aging trend intensified over time $(P$ trend $=0.003)$. The proportion of patients ages $\geq 80$ years increased from
$32.4 \%$ in 2009 to $41.3 \%$ in 2017 . We believe that the pattern of AECOPD patients relates to the aging population in general, as the proportion of people ages $\geq 80$ years in Beijing increased from $1.8 \%$ in 2009 to $2.6 \%$ in 2017. The proportion of patients diagnosed with COPD was higher than that of the three other sub-diseases, and increased significantly over time (68.4\% in 2009 and $84.7 \%$ in $2017, P$ trend $<0.001)$. Over two-thirds of the admissions were at tertiary hospitals and the proportion did not change significantly during the study period ( $\mathrm{P}$ trend $=0.324)$. The mean LOS decreased significantly at an annual rate of $1.1 \%$ (except for a slight increase in 2014; P trend $<0.001$ ). Over the study period, the share of drug costs in total expenditures dropped from $52.9 \%$ to $39.4 \%$ (P trend $<0.001$ ).

In 2009, mean expenditures per admission were 19,760 CNY, which was greater than the median of $13,046 \mathrm{CNY}$ (Table 2). Expenditures increased at an average annual growth rate of $0.11 \%$, indicating no significant increase over time ( $\mathrm{P}$ trend $=0.697)$. As the standard deviation of expenditures decreased, so did the 99th percentile expenditures, which could be the result of decreased expenditures among the highest paying patients and increased expenditures among the lowest paying patients.

Some similar patterns are noted for annual expenditures per patient (Table 3). The mean per capita expenditure was 21,190 CNY in 2009, which was greater than the mean per admission expenditure. The annual growth rate of mean expenditure per capita was $1.7 \%$, which was more than 15 times the mean expenditure per admission. The cause of the difference between the two indicators was a progressive increase in the annual number of admissions for AECOPD (from 1.2 times in 2009 to 1.5 times in 2017 (Figure 1)). Of the increase in per capita expenditure, $93.5 \%$ is attributable to the increase in the number of admissions, and only $6.5 \%$ is attributable to the increase in expenditures per admission (Table 4). The increased number of admissions was likely driven by increased readmissions for a small group of patients, as the fraction of patients with four or more admissions per year increased from $1.5 \%$ in 2009 to $5.4 \%$ in 2017 (Figure 2). The standard deviation of the 99th percentile expenditures also increased over time, reflecting different patterns compared with those for per admission expenditures.

We compare the temporal trends in per admission and per capita expenditures by subgroups, and the corresponding results are displayed in Figures 3 and 4, respectively. As shown in Figure 3A, per admission expenditures for men 
Table I Characteristics of Admissions for Acute Exacerbations of Chronic Obstructive Pulmonary Disease (AECOPD) in Beijing from 2009 to 2017

\begin{tabular}{|c|c|c|c|c|c|c|c|c|c|c|}
\hline & 2009 & 2010 & 2011 & 2012 & 2013 & 2014 & 2015 & 2016 & 2017 & $\mathbf{P}$ \\
\hline Number & 25,433 & 29,163 & 30,151 & 35,825 & 40,423 & 45,442 & 34,844 & 37,179 & 36,656 & $<0.001^{c}$ \\
\hline \multicolumn{11}{|l|}{ Gender, n (\%) } \\
\hline Male & $\begin{array}{l}14,946 \\
58.8 \%\end{array}$ & $\begin{array}{l}17,235 \\
59.1 \%\end{array}$ & $\begin{array}{l}17,838 \\
59.2 \%\end{array}$ & $\begin{array}{l}21,794 \\
60.8 \%\end{array}$ & $\begin{array}{l}25,130 \\
62.2 \%\end{array}$ & $\begin{array}{l}29,567 \\
65.1 \%\end{array}$ & $\begin{array}{l}23,170 \\
66.5 \%\end{array}$ & $\begin{array}{l}25,279 \\
68.0 \%\end{array}$ & $\begin{array}{l}25,214 \\
68.8 \%\end{array}$ & \multirow[t]{2}{*}{$<0.001^{d}$} \\
\hline Female & $\begin{array}{l}10,487 \\
41.2 \%\end{array}$ & $\begin{array}{l}11,928 \\
40.9 \%\end{array}$ & $\begin{array}{l}12,313 \\
40.8 \%\end{array}$ & $\begin{array}{l}|4,03| \\
39.2 \%\end{array}$ & $\begin{array}{l}15,293 \\
37.8 \%\end{array}$ & $\begin{array}{l}15,875 \\
34.9 \%\end{array}$ & $\begin{array}{l}11,674 \\
33.5 \%\end{array}$ & $\begin{array}{l}11,900 \\
32.0 \%\end{array}$ & $\begin{array}{l}11,442 \\
31.2 \%\end{array}$ & \\
\hline \multicolumn{11}{|l|}{ Age, n (\%) } \\
\hline $18 \sim 39$ yrs & $\begin{array}{l}340 \\
1.3 \%\end{array}$ & $\begin{array}{l}366 \\
1.3 \%\end{array}$ & $\begin{array}{l}345 \\
1.1 \%\end{array}$ & $\begin{array}{l}392 \\
1.1 \%\end{array}$ & $\begin{array}{l}414 \\
1.0 \%\end{array}$ & $\begin{array}{l}405 \\
0.9 \%\end{array}$ & $\begin{array}{l}361 \\
1.0 \%\end{array}$ & $\begin{array}{l}438 \\
1.20 \%\end{array}$ & $\begin{array}{l}404 \\
1.1 \%\end{array}$ & \multirow[t]{5}{*}{$0.003^{e}$} \\
\hline $40 \sim 59$ yrs & $\begin{array}{l}2,247 \\
8.8 \%\end{array}$ & $\begin{array}{l}2,351 \\
8.1 \%\end{array}$ & $\begin{array}{l}2,413 \\
8.0 \%\end{array}$ & $\begin{array}{l}3,010 \\
8.4 \%\end{array}$ & $\begin{array}{l}3,734 \\
9.2 \%\end{array}$ & $\begin{array}{l}4,470 \\
9.8 \%\end{array}$ & $\begin{array}{l}3,091 \\
8.9 \%\end{array}$ & $\begin{array}{l}2,961 \\
8.0 \%\end{array}$ & $\begin{array}{l}2,800 \\
7.6 \%\end{array}$ & \\
\hline $60 \sim 69$ yrs & $\begin{array}{l}3,696 \\
14.5 \%\end{array}$ & $\begin{array}{l}4,057 \\
13.9 \%\end{array}$ & $\begin{array}{l}4,184 \\
13.9 \%\end{array}$ & $\begin{array}{l}5,197 \\
14.5 \%\end{array}$ & $\begin{array}{l}6,294 \\
15.6 \%\end{array}$ & $\begin{array}{l}8,07 \mid \\
\mid 7.8 \%\end{array}$ & $\begin{array}{l}6,760 \\
19.4 \%\end{array}$ & $\begin{array}{l}7,736 \\
20.8 \%\end{array}$ & $\begin{array}{l}7,969 \\
21.7 \%\end{array}$ & \\
\hline 70 79 yrs & $\begin{array}{l}10,897 \\
42.8 \%\end{array}$ & $\begin{array}{l}11,923 \\
40.9 \%\end{array}$ & $\begin{array}{l}|I, 76| \\
39.0 \%\end{array}$ & $\begin{array}{l}13,262 \\
37.0 \%\end{array}$ & $\begin{array}{l}13,684 \\
33.9 \%\end{array}$ & $\begin{array}{l}|4,33| \\
31.5 \%\end{array}$ & $\begin{array}{l}10,566 \\
30.3 \%\end{array}$ & $\begin{array}{l}10,940 \\
29.4 \%\end{array}$ & $\begin{array}{l}10,355 \\
28.2 \%\end{array}$ & \\
\hline$\geq 80$ yrs & $\begin{array}{l}8,253 \\
32.4 \%\end{array}$ & $\begin{array}{l}10,466 \\
35.9 \%\end{array}$ & $\begin{array}{l}1 \mathrm{I}, 448 \\
38.0 \%\end{array}$ & $\begin{array}{l}13,964 \\
39.0 \%\end{array}$ & $\begin{array}{l}16,297 \\
40.3 \%\end{array}$ & $\begin{array}{l}18,165 \\
40.0 \%\end{array}$ & $\begin{array}{l}14,066 \\
40.4 \%\end{array}$ & $\begin{array}{l}15,104 \\
40.6 \%\end{array}$ & $\begin{array}{l}15,128 \\
41.3 \%\end{array}$ & \\
\hline \multicolumn{11}{|l|}{ Disease type, ${ }^{\mathrm{a}} \mathrm{n}(\%)$} \\
\hline Emphysema & $\begin{array}{l}228 \\
0.9 \%\end{array}$ & $\begin{array}{l}220 \\
0.8 \%\end{array}$ & $\begin{array}{l}134 \\
0.4 \%\end{array}$ & $\begin{array}{l}152 \\
0.4 \%\end{array}$ & $\begin{array}{l}153 \\
0.4 \%\end{array}$ & $\begin{array}{l}139 \\
0.3 \%\end{array}$ & $\begin{array}{l}115 \\
0.3 \%\end{array}$ & $\begin{array}{l}147 \\
0.4 \%\end{array}$ & $\begin{array}{l}154 \\
0.4 \%\end{array}$ & \multirow[t]{4}{*}{$<0.001^{\mathrm{e}}$} \\
\hline Bull ${ }^{\mathrm{a}}$ & $\begin{array}{l}274 \\
1.1 \%\end{array}$ & $\begin{array}{l}329 \\
1.1 \%\end{array}$ & $\begin{array}{l}324 \\
1.1 \%\end{array}$ & $\begin{array}{l}361 \\
1.0 \%\end{array}$ & $\begin{array}{l}370 \\
0.9 \%\end{array}$ & $\begin{array}{l}383 \\
0.8 \%\end{array}$ & $\begin{array}{l}401 \\
1.2 \%\end{array}$ & $\begin{array}{l}417 \\
1.1 \%\end{array}$ & $\begin{array}{l}380 \\
1.0 \%\end{array}$ & \\
\hline Bronchitis & $\begin{array}{l}7,523 \\
29.6 \%\end{array}$ & $\begin{array}{l}8,023 \\
27.5 \%\end{array}$ & $\begin{array}{l}7,605 \\
25.2 \%\end{array}$ & $\begin{array}{l}8,378 \\
23.4 \%\end{array}$ & $\begin{array}{l}8,753 \\
21.7 \%\end{array}$ & $\begin{array}{l}10,966 \\
24.1 \%\end{array}$ & $\begin{array}{l}5,475 \\
15.7 \%\end{array}$ & $\begin{array}{l}5,555 \\
14.9 \%\end{array}$ & $\begin{array}{l}5,062 \\
13.8 \%\end{array}$ & \\
\hline COPD & $\begin{array}{l}17,408 \\
68.4 \%\end{array}$ & $\begin{array}{l}20,591 \\
70.6 \%\end{array}$ & $\begin{array}{l}22,088 \\
73.3 \%\end{array}$ & $\begin{array}{l}26,934 \\
75.2 \%\end{array}$ & $\begin{array}{l}31,147 \\
77.1 \%\end{array}$ & $\begin{array}{l}33,954 \\
74.7 \%\end{array}$ & $\begin{array}{l}28,853 \\
82.8 \%\end{array}$ & $\begin{array}{l}31,060 \\
83.5 \%\end{array}$ & $\begin{array}{l}31,060 \\
84.7 \%\end{array}$ & \\
\hline \multicolumn{11}{|l|}{ Hospital level, n (\%) } \\
\hline Level 2 (secondary) & $\begin{array}{l}7,396 \\
29.1 \%\end{array}$ & $\begin{array}{l}8,739 \\
30.0 \%\end{array}$ & $\begin{array}{l}9,214 \\
30.6 \%\end{array}$ & $\begin{array}{l}11,157 \\
31.1 \%\end{array}$ & $\begin{array}{l}12,326 \\
30.5 \%\end{array}$ & $\begin{array}{l}14,135 \\
31.1 \%\end{array}$ & $\begin{array}{l}10,521 \\
30.2 \%\end{array}$ & $\begin{array}{l}11,117 \\
29.9 \%\end{array}$ & $\begin{array}{l}10,708 \\
29.2 \%\end{array}$ & \multirow[t]{2}{*}{$0.324^{\mathrm{d}}$} \\
\hline Level 3 (tertiary) & $\begin{array}{l}18,037 \\
70.9 \%\end{array}$ & $\begin{array}{l}20,424 \\
70.0 \%\end{array}$ & $\begin{array}{l}20,937 \\
69.4 \%\end{array}$ & $\begin{array}{l}24,668 \\
68.9 \%\end{array}$ & $\begin{array}{l}28,097 \\
69.5 \%\end{array}$ & $\begin{array}{l}31,307 \\
68.9 \%\end{array}$ & $\begin{array}{l}24,323 \\
69.8 \%\end{array}$ & $\begin{array}{l}26,062 \\
70.1 \%\end{array}$ & $\begin{array}{l}25,948 \\
70.8 \%\end{array}$ & \\
\hline $\begin{array}{l}\text { Mean of LOS (days) } \\
\text { Proportion of drug cost }{ }^{\mathrm{b}}(\%)\end{array}$ & $\begin{array}{l}16.0 \\
52.9 \%\end{array}$ & $\begin{array}{l}15.9 \\
52.3 \%\end{array}$ & $\begin{array}{l}15.4 \\
48.8 \%\end{array}$ & $\begin{array}{l}14.5 \\
48.1 \%\end{array}$ & $\begin{array}{l}14.1 \\
47.2 \%\end{array}$ & $\begin{array}{l}14.3 \\
46.7 \%\end{array}$ & $\begin{array}{l}14.0 \\
45.5 \%\end{array}$ & $\begin{array}{l}13.8 \\
45.8 \%\end{array}$ & $\begin{array}{l}13.5 \\
39.4 \%\end{array}$ & $\begin{array}{l}<0.00 I^{f} \\
<0.00 I^{g}\end{array}$ \\
\hline
\end{tabular}

Notes: ${ }^{a}$ Disease types: All patients with AECOPD were subdivided into four types according to ICD-10 codes for AECOPD. ${ }^{b}$ Drug cost includes costs for Western medicine and Chinese traditional medicine. ${ }^{C} P$-value for time trend estimated using Poisson regression. ${ }^{d} P$-value for time trend estimated using logistic regression. ${ }^{e}$-value for time trend estimated using multinomial logit regression. ${ }^{f} P$-value of the Kruskal-Wallis test comparing LOS in different year groups. ${ }^{g} P$-value for time trend estimated using linear regression.

Abbreviations: COPD, chronic obstructive pulmonary disease; LOS: length of stay.

were higher than those for women from 2009 to 2013, and close to or slightly less than those for women in subsequent years. The decrease in the size of the spending gap between men and women patients was the result of decreased spending for men and increased spending for women. Although expenditures per admission decreased for men, it is likely 
Table 2 Hospitalization Costs (CNY) per Admission for Patients with Acute Exacerbations of Chronic Obstructive Pulmonary Disease (AECOPD) in Beijing (2009-2017, $\mathrm{n}=315,116)$

\begin{tabular}{|l|l|l|l|l|l|l|l|l|}
\hline Year & $\mathbf{N}$ & Mean & Median & P25 & P75 & P99 & SD & $P^{\mathbf{a}}$ \\
\hline 2009 & 25,433 & 19,760 & 13,046 & 8,146 & 21,526 & 126,462 & 31,399 \\
2010 & 29,163 & 21,220 & 13,812 & 8,820 & 22,326 & 141,207 & 40,993 \\
2011 & 30,151 & 20,154 & 13,303 & 8,744 & 20,855 & 133,972 & 34,290 \\
2012 & 35,825 & 19,835 & 13,561 & 8,974 & 21,183 & 127,197 & 29,743 \\
2013 & 40,423 & 19,684 & 13,833 & 9,386 & 21,546 & 109,310 & 27,706 \\
2014 & 45,442 & 19,935 & 13,964 & 9,715 & 21,447 & 114,761 & 27,190 \\
2015 & 34,844 & 20,571 & 14,908 & 10,300 & 22,615 & 109,336 & 24,365 \\
2016 & 37,179 & 20,567 & 14,995 & 10,498 & 23,256 & 104,092 & 22,816 \\
2017 & 36,656 & 20,118 & 14,843 & 10,526 & 22,632 & 101,666 & 21,550 \\
\hline
\end{tabular}

Notes: ${ }^{a} P$-value for time trend estimated using linear regression. All costs shown are adjusted for the increment of inflation in 2017.

Abbreviations: CNY, Chinese yuan; P25, 25th percentile; P50, 50th percentile; P75, 75th percentile; P99, 99th percentile; SD, standard deviation.

Table 3 Hospitalization Costs (CNY) per Capita for Patients with Acute Exacerbations of Chronic Obstructive Pulmonary Disease (AECOPD) in Beijing (2009-2017)

\begin{tabular}{|l|l|l|l|l|l|l|l|l|}
\hline Year & N & Mean & Median & P25 & P75 & P99 & SD & Pa $^{\mathbf{a}}$ \\
\hline 2009 & 21,190 & 23,716 & 13,589 & 8,225 & 24,420 & 17,5770 & 40,942 \\
2010 & 23,652 & 26,165 & 14,565 & 8,983 & 26,052 & 19,6495 & 53,238 \\
2011 & 23,863 & 25,464 & 14,199 & 8,966 & 25,125 & 20,8785 & 50,617 \\
2012 & 27,301 & 26,028 & 14,638 & 9,307 & 25,761 & 19,9303 & 49,470 \\
2013 & 28,642 & 27,780 & 15,335 & 9,749 & 27,375 & 20,8753 & 55,251 \\
2014 & 30,411 & 29,788 & 16,384 & 10,237 & 29,524 & 21,9803 & 56,879 \\
2015 & 23,257 & 30,820 & 16,905 & 10,435 & 30,892 & 23,6891 & 51,010 & \\
2016 & 24,588 & 31,099 & 17,587 & 10,905 & 31,616 & 22,5724 & 49,140 & \\
2017 & 23,788 & 31,000 & 17,542 & 11,106 & 31,424 & 21,7764 & 49,695 \\
\hline
\end{tabular}

Notes: ${ }^{2} P$-value for time trend estimated using linear regression. CNY: Chinese yuan. All costs shown are adjusted for the increment of inflation in 2017. Abbreviations: P25, 25th percentile; P50, 50th percentile; P75, 75th percentile; P99, 99th percentile; SD, standard deviation.

that the number of admissions increased for men after 2013 and the difference in per capita expenditures between men and women remained stable (Figure 4A). Annual per capita expenditures among patients ages $\geq 80$ years, were much higher than those of other age groups and remained stable

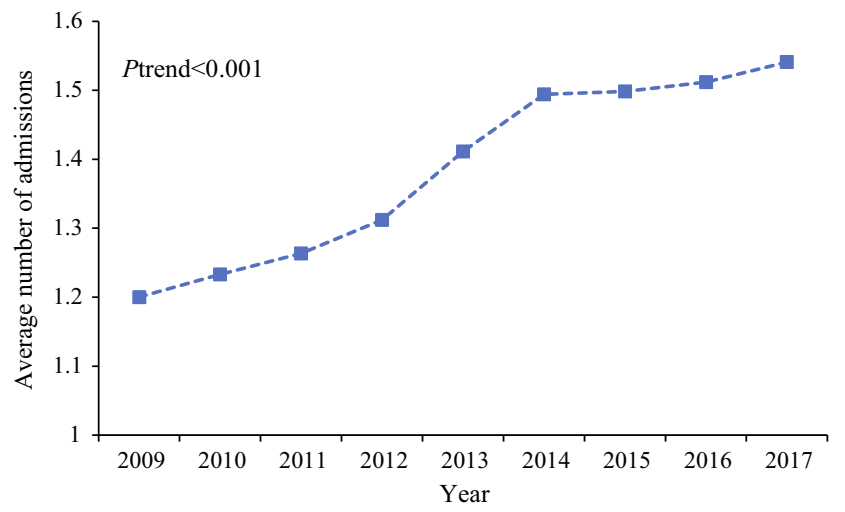

Figure I Annual average number of admissions per capita.
Table 4 Contribution of Increased per Admission Expenditures and Number of Admissions to Increased per Capita Expenditures Based on Their Annual Growth Rate for AECOPD Hospitalizations in Beijing (2009-2017)

\begin{tabular}{|l|l|l|l|}
\hline & $\begin{array}{l}\text { Per capita } \\
\text { Expenditures }\end{array}$ & $\begin{array}{l}\text { Number of } \\
\text { Admissions }\end{array}$ & $\begin{array}{l}\text { Per admission } \\
\text { Expenditures }\end{array}$ \\
\hline $\begin{array}{l}\text { Annual } \\
\text { growth rate (\%) } \\
\text { Contribution }\end{array}$ & 1.7 & 1.6 & 0.1 \\
\hline
\end{tabular}

Notes: ${ }^{2}$ Contributions were calculated by the annual growth rate of per admission expenditures or the number of admissions divided by the annual growth rate of per admission expenditures $\times 100 \%$

Abbreviation: AECOPD, acute exacerbation of chronic obstructive pulmonary disease.

(Figure 4B). However, per admission expenditures increased among patients ages 18-39 years over the sample period (Figure 3B). It is possible that young adults' health conditions worsened for various reasons, such as air pollution or high levels of pressure in the workplace. Among the four types of diseases, patients with bulla had the highest per 


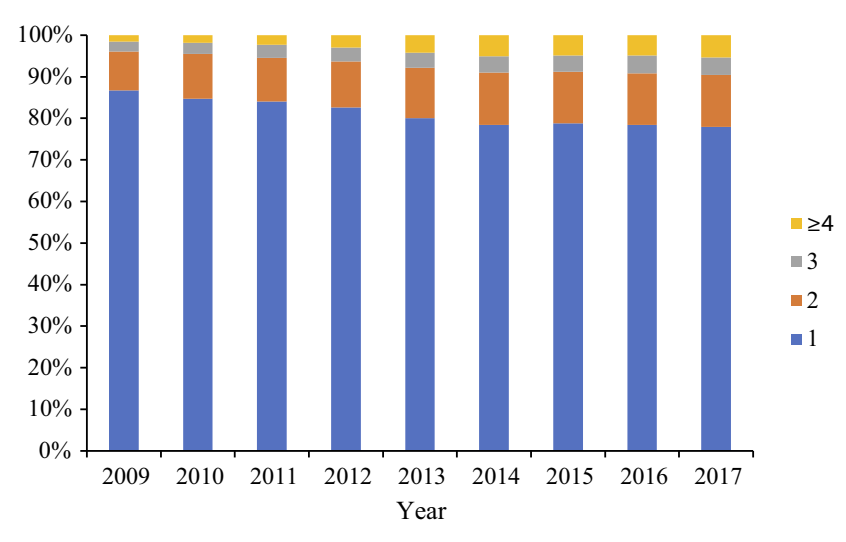

Figure 2 Distribution of the number of admissions per person per year.

admission expenditures, followed by emphysema, COPD, and bronchitis. Patients with bulla experienced the most rapid increase in expenditures (Figure 3C) because those patients were more likely to receive lung volume reduction procedures. Their expenditures were higher than those of the patients in the other disease categories. The trends were mostly similar for per capita expenditures, but COPD had the second highest per capita, which increased by $30.3 \%$ (Figure 4C). For patients that were admitted to tertiary
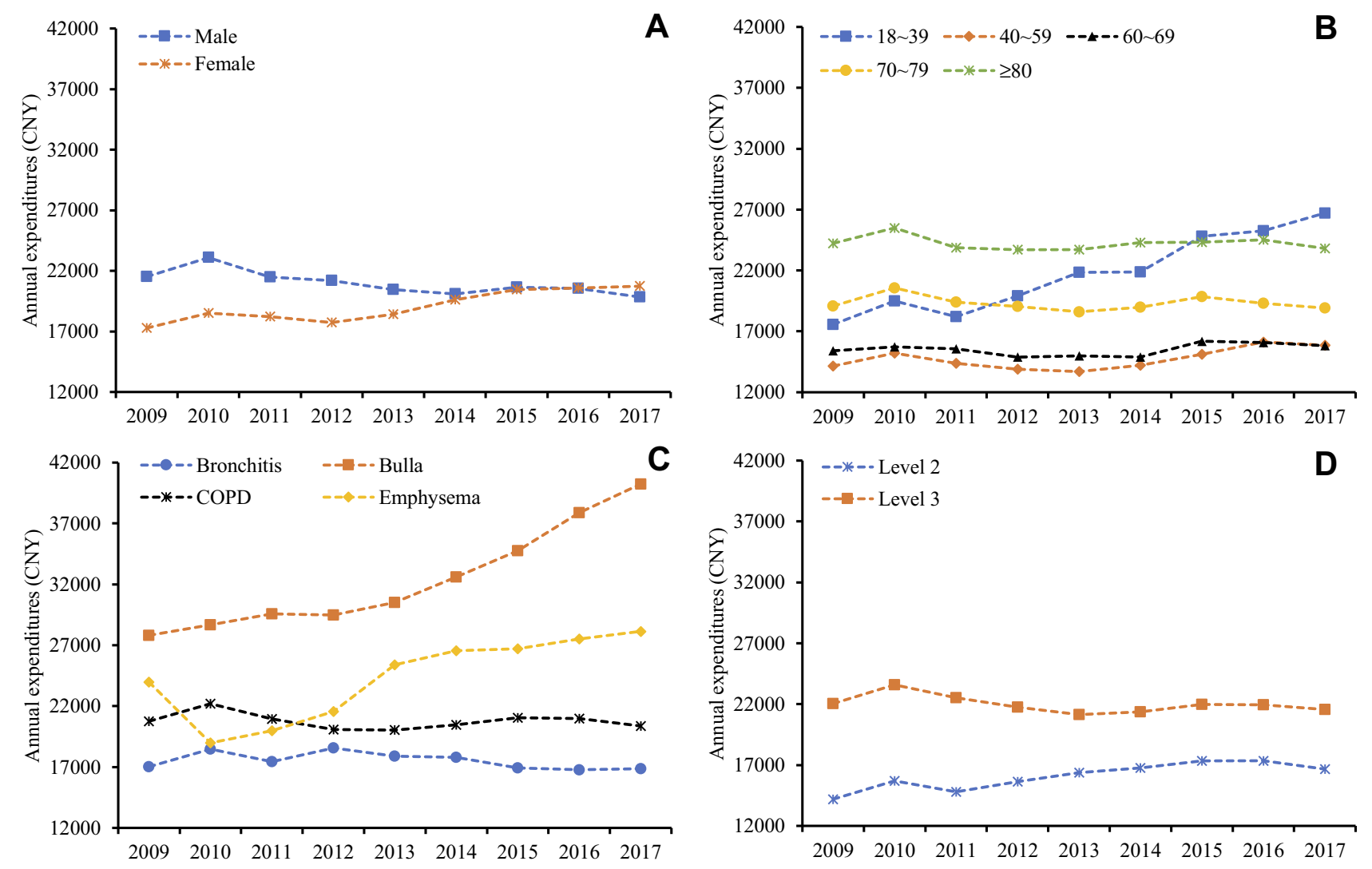

hospitals, the per admission and per capita expenditures were higher than those of patients admitted to secondary hospitals (Figures 3D and 4D). Compared with secondary hospitals, tertiary hospitals are more comprehensive and usually admit patients with more severe conditions. Per capita expenditures for tertiary hospitals have continued to increase since 2012 (Figure 4D). The difference in per admission costs between tertiary and secondary hospitals narrowed and remained stable after 2012 (Figure 3D).

The results of the multivariate regression analysis are shown in Table 5. Consistent with the descriptive evidence, the findings are that being male, being elderly, having bulla, being treated at a tertiary hospital, and having a longer inpatient stay are all associated with increased per admission expenditures. Similar patterns are seen for increased per capita expenditures, which are also significantly associated with the number of admissions.

\section{Discussion}

\section{Hospitalization Costs}

There has been a lack of literature using national or citywide long-term data, to analyze annual hospitalization

Figure 3 Expenditures per admission from 2009 to 2017. (A) Gender-specific expenditures per admission. (B) Age-specific expenditures per admission. (C) Disease typespecific expenditures per admission. (D) Hospital level-specific expenditures per admission. 

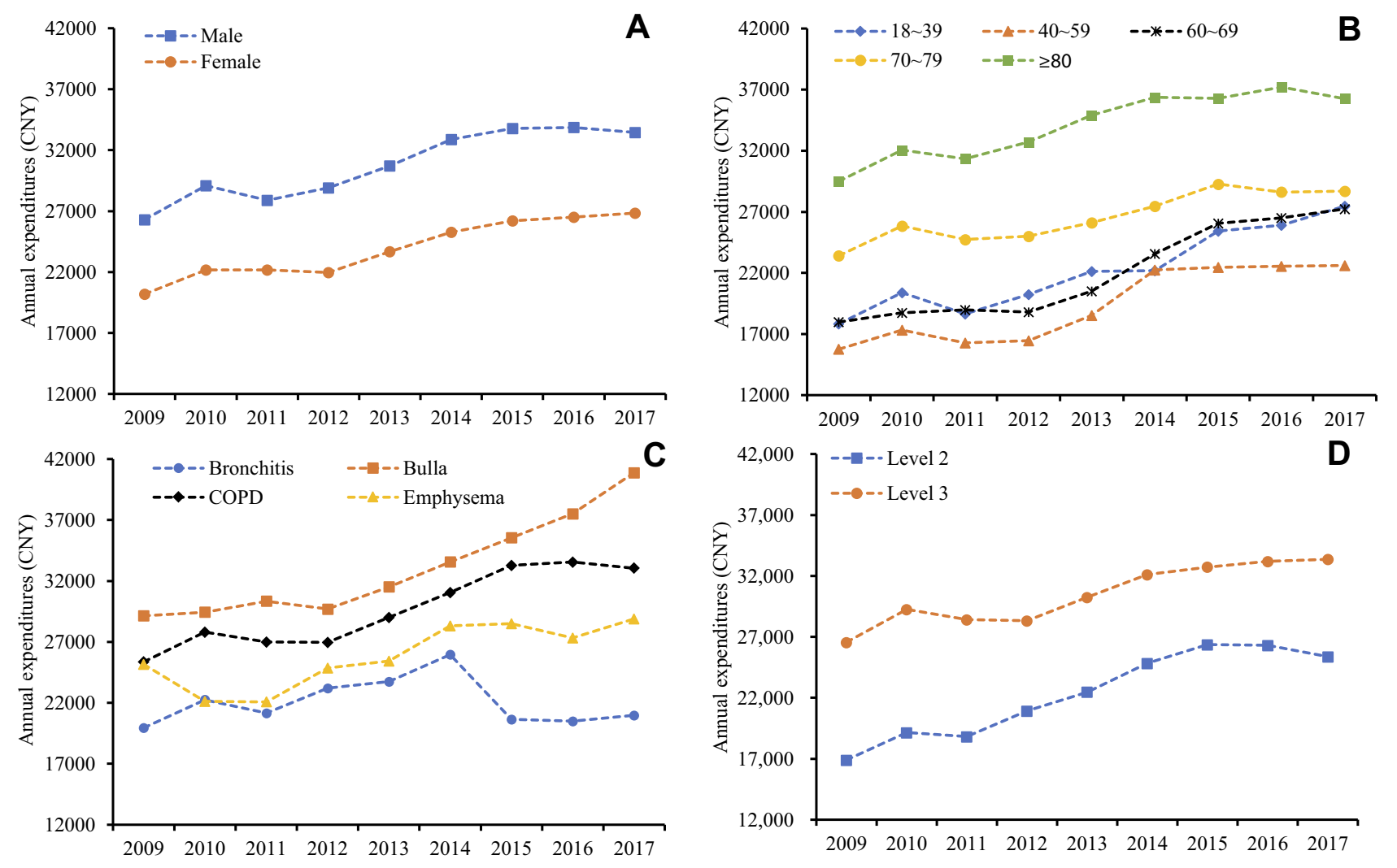

Figure 4 Annual expenditures per capita from 2009 to 2017. (A) Gender-specific annual expenditures per capita. (B) Age-specific annual expenditures per capita. (C) Disease type-specific annual expenditures per capita. (D) Hospital level-specific annual expenditures per capita.

costs for AECOPD in China. Some studies have provided limited evidence based on smaller samples from a few hospitals or communities. ${ }^{14,15}$ However, our study is the first to use the full sample of AECOPD patients admitted to secondary and tertiary hospitals in one of the largest cities in China. We find that the mean (standard deviation) of inpatient expenditures per admission for AECOPD was 17,862 CNY (30391 CNY) in 2011. The expenditures were then deflated at the 2011 level, to make comparisons with other studies. This level of expenditures is higher than those reported in a cross-sectional study of four cities in China in 2011, which finds expenditures of 6,120 CNY (17,755 CNY) in Beijing, 3,938 CNY (8,318 CNY) in Guangzhou, 3,171 CNY $(5,644 \mathrm{CNY})$ in Shanghai, and $5,001 \mathrm{CNY}(7,824 \mathrm{CNY})$ in Chengdu. ${ }^{15}$ The difference is because the samples in the other study include comprehensive (or tertiary) hospitals and community health centers. The latter only admit patients without severe conditions and usually have a lower level of expenditures. In contrast, a study that uses data from a tertiary hospital in Guangzhou, reports higher hospitalization costs, at $24,373 \mathrm{CNY}(44,174 \mathrm{CNY})$ in $2016 .{ }^{14}$ Our estimate for
2016 is 20,243 CNY $(22,457$ CNY), with expenditures adjusted to $2016 \mathrm{CNY}$. If we restrict the samples to patients in tertiary hospitals, the per admission expenditures that were 21,574 $(23,969) \mathrm{CNY}$ in 2016, become closer to the estimates in Guangzhou.

The reduction in hospital expenditures may have effects on overall medical expenditures as well. Care for COPD and exacerbations may be delivered in many settings, from inpatient stays to clinics or nursing care. A reduction in inpatient care may result in patients being transferred to outpatient care or nursing care. However, due to data limitations, we cannot investigate the patterns in outpatient visits or expenditures. Other than public hospitals in Beijing, few medical institutions are available to provide nursing care for patients who are readmitted repeatedly, so the impact of transferring patients is expected to be small.

Various studies find wide variability in hospitalization costs in different countries. The mean hospitalization costs for AECOPD per capita were $\$ 38,455$ in the United State in $2010,{ }^{20} \$ 1765$ in Turkey between 2010 and 2011, ${ }^{16}$ $\$ 1593$ in Sweden in $2013,{ }^{10} \$ 2150$ in Italy between 2008 
Table 5 Contributing Factors to per Admission Expenditures and per Capita Expenditures for AECOPD Hospitalizations in Beijing (2009-2017)

\begin{tabular}{|c|c|c|c|c|}
\hline \multirow[t]{2}{*}{ Factor } & \multicolumn{2}{|c|}{ Per admission Expenditures ( $\times 1000 \mathrm{CNY}$ ) } & \multicolumn{2}{|c|}{ Per capita Expenditures ( $\times 1000 \mathrm{CNY})$} \\
\hline & $\beta(95 \% \mathrm{Cl})$ & $P$ & $\beta(95 \% \mathrm{Cl})$ & $\boldsymbol{P}$ \\
\hline Gender $($ female $=0$ ) & $0.203(0.026,0.38 I)$ & 0.025 & $1.048(0.718,1.378)$ & $<0.001$ \\
\hline $\begin{array}{l}\text { Hospital level (level } 2=0 \text { ) } \\
\quad \text { Level } 3\end{array}$ & $5.218(5.034,5.402)$ & $<0.001$ & $7.195(6.847,7.544)$ & $<0.001$ \\
\hline $\begin{array}{l}\text { Age, years }(18 \sim 30=0) \\
\quad 40 \sim 59 \\
60 \sim 69 \\
70 \sim 79 \\
\geq 80\end{array}$ & $\begin{array}{l}-1.060(2.042,-0.077) \\
-0.875(-1.854,0.105) \\
2.477(1.505,3.449) \\
5.760(4.788,6.73 I)\end{array}$ & $\begin{array}{l}0.025 \\
0.080 \\
<0.001 \\
<0.001\end{array}$ & $\begin{array}{l}-1.593(-3.212,0.027) \\
-1.422(-3.038,0.195) \\
2.951(1.351,4.550) \\
8.090(6.491,9.689)\end{array}$ & $\begin{array}{l}0.054 \\
0.085 \\
<0.001 \\
<0.001\end{array}$ \\
\hline $\begin{array}{l}\text { Disease type (bronchitis }=0 \text { ) } \\
\text { COPD } \\
\text { Emphysema } \\
\text { Bulla }\end{array}$ & $\begin{array}{l}2.559(2.349,2.768) \\
9.140(7.849,10.430) \\
18.641(17.654,19.629)\end{array}$ & $\begin{array}{l}<0.001 \\
<0.001 \\
<0.001\end{array}$ & $\begin{array}{l}2.692(2.311,3.074) \\
9.198(7.044,11.352) \\
18.496(16.861,20.130)\end{array}$ & $\begin{array}{l}<0.001 \\
<0.001 \\
<0.001\end{array}$ \\
\hline Length of stay (days) & $1.008(1.002,1.014)$ & $<0.001$ & $1.084(1.074,1.094)$ & $<0.001$ \\
\hline Number of admissions & & & $20.29(20.165,20.414)$ & $<0.001$ \\
\hline
\end{tabular}

Notes: Adjusted for year fixed effects in the multivariable linear regression model.

Abbreviations: AECOPD, acute exacerbation of chronic obstructive pulmonary disease; $\mathrm{Cl}$, confidence interval; CNY, Chinese yuan.

and $2012,{ }^{17}$ and $\$ 921$ in Greece in $2015 .{ }^{22}$ Such variations across countries can be attributed to differences in health care systems, insurance coverage, geographical conditions, population income, and treatment patterns, and so forth. Compared with these results, our estimations of the annual hospitalization costs in Beijing are relatively high. There are several potential reasons for this. First, our sample is from Beijing, where the population is richer and has higher ability to pay. Also, medical pricing may not set the appropriate incentives for physicians and hospitals to save costs. An example is that the price of magnetic resonance imaging technology is high, and it may be overused in practice. Another reason is that the LOS for patients in China with AECOPD is longer than that in many other countries. Our admissions data exclude primary hospitals and community health centers. Therefore, the data represents patients with relatively worse health statuses and higher expenditures. We would like to emphasize that the diagnosis criteria is different across studies, so the value of comparisons may be limited.

\section{Trend and Multivariate Analysis}

Although we find significantly increasing trends in annual per capita expenditures, we do not find the same trend in per admission expenditures. The annual growth rate of per capita expenditures was more than 15 times than of per admission expenditures. These differences are mainly due to the increase in the number of admissions (Figure 1), which in turn contributed to the increase in per capita expenditures (93.5\%). The increase in the number of admissions over time may have been driven by various factors, although we cannot identify them due to data limitations. Health conditions of the population became worse in general, so the demand for health care increased. People's incomes increased over time, so their ability to pay for health care increased and they faced less financial constraint. Along with that, health care reform increased readmissions. In 2009, the government in China initiated a new wave of health care reform in an attempt to control the increasing medical costs. Since then, several policies have been implemented in Beijing, such as the introduction of the Essential Drug List, elimination of profits on drug sales, and reform of the insurance payment system. Our results suggest that per admission expenditures were overall controlled. However, the quality of care may have been affected and hence readmission rates increased. The government should consider policies to control total costs, such as supervising readmissions or improving the management of patients with COPD at stable stage. Due to the rapid increases in the number of admissions, per capita expenditures and the financial burden on patients increased. 
The increased per capita income and generosity of insurance reimbursement, may also account for the increases in per capita expenditures.

The two indicators show that there were different trends by age, gender, and disease type. Although male patients generally bore higher costs, per admission expenditures among female patients began to increase in 2012 and even exceeded those among male patients in 2017 (Figure 3A). We also find that the elderly generally had a higher economic burden due to their conditions and had more hospitalizations for acute exacerbations (Figures 3B and $4 \mathrm{~B}$ ). Our analysis is the first to report age and genderspecific effects on the increase in expenditures in China that were consistent with previous findings in other countries. ${ }^{13,16,24,25}$ Due to competing health priorities, most previous studies primarily focused on hospitalization costs among patients older than 60 years of age, and less so on patients younger than 40 years. Our analysis of the adult population of all ages provides a broader view of the spending patterns of various subgroups.

The multivariate analysis shows that the relationship persisted between increasing expenditures and the introductory contributing factors. Similar findings have been found in previous studies. ${ }^{12-15,24-26}$ After multivariate adjustment, the regression analyses show that genderspecific effects on per capita expenditures were apparently larger than those on per admission expenditures (Table 5).

We also found significantly decreased trends for LOS and the proportion of drug costs in total expenditures. We believe that the trends were mainly driven by health care reform. The insurance payment reform may have changed hospitals' incentives, but reducing LOS is one effective way to control costs. Also, eliminating profits on drug sales decreased drug prices and expenditures. A consistent finding across countries is the association between increased LOS and hospitalization costs. ${ }^{20,27,28}$ However, our findings show a declining trend in mean LOS and an increasing trend in per capita expenditures. This suggests that shortening LOS does not necessarily reduce hospitalization costs (especially not per capita expenditures) due to the increased number of admissions. The proportion of drug costs in total expenditures decreased during the course of the study, yet this did not result in a reduction in hospitalization costs. These changes occurred during the same period as the implementation of China's health care reform of $2009 .^{23,29}$ This suggests that the health care reform policy that restricted the maximum proportion of drug costs and LOS, did not reduce the direct economic burden of AECOPD due to the simultaneous increase in the frequency of admissions.

\section{Strengths and Limitations}

This study has several important strengths. We used citywide data for a wide range of ages to determine nineyear trends in hospitalization costs. Given that COPD is a chronic disease characterized by multiple acute exacerbations requiring hospitalization, we identified per capita expenditures as a better index than per admission expenditures due to the former's reflection of the increased direct burden of the number of admissions. To the best of our knowledge, this is the first study to assess per admission and per capita expenditures in China and outline their distinct temporal trends and contributing factors. Our longitudinal data from 2009 to 2017 made it possible to assess the impact of China's health care reform of $2009^{23,29}$ on the patterns of hospitalization costs over time and related factors, such as LOS and the proportion of drug costs.

The study has several data limitations. Our database did not allow us to explore the potential effects of some information on hospitalization costs, such as income and insurance, the severity of the exacerbations, comorbidity, pharmacologic treatments, or use of mechanical ventilation. Also, our data for each patient included a single variable on the total reimbursed expenditures. Details such as reimbursement by service categories were not available. The data was collected in only one city, therefore our results and conclusions may not be generalizable to other regions in China. The data also did not include pulmonary function tests to confirm that the patients actually had correct diagnosis of COPD. There was no information available on the use of specific classes of COPD medications that are known to reduce the risk of exacerbation, which could in turn influence hospitalizations and their costs.

\section{Conclusion}

The findings of the study indicate significantly increasing trends in inpatient per capita expenditures in Beijing, China, from 2009 to 2017, despite the decline in LOS and the proportion of drug costs. These changes in LOS and drug costs embody the effectiveness of China's health care reform of 2009. Future strategies to reduce hospitalizations and especially readmissions of COPD patients are needed. 


\section{Author contributions}

JS takes responsibility for the content of the manuscript, including the data and analysis. All authors contributed to data analysis, drafting and revising the article, gave final approval of the version to be published, and agree to be accountable for all aspects of the work.

\section{Disclosure}

The authors report no conflicts of interest in this work.

\section{References}

1. Kadel R. GBD 2017 causes of death collaborators. Global, regional, and national age-sex-specific mortality for 282 causes of death in 195 countries and territories, 1980-2017: a systematic analysis for the global burden of disease study 2017. Lancet. 2018;392:1736-1788.

2. Zhou M, Wang H, Zeng X, et al. Mortality, morbidity, and risk factors in China and its provinces, 1990-2017: a systematic analysis for the global burden of disease study 2017. Lancet. 2019;394 (10204):1145-1158. doi:10.1016/S0140-6736(19)30427-1

3. Zhong N, Wang C, Yao W, et al. Prevalence of chronic obstructive pulmonary disease in China: a large, population-based survey. $\mathrm{Am}$ J Respir Crit Care Med. 2007;176(8):753-760. doi:10.1164/rccm.20 0612-1749OC

4. Wang C, Xu J, Yang L, et al. Prevalence and risk factors of chronic obstructive pulmonary disease in China (the China Pulmonary Health [CPH] study): a national cross-sectional study. Lancet. 2018;391 (10131):1706-1717. doi:10.1016/S0140-6736(18)30841-9

5. Donaldson GC, Seemungal TA, Bhowmik A, Wedzicha JA. Relationship between exacerbation frequency and lung function decline in chronic obstructive pulmonary disease. Thorax. 2002;57 (10):847-852. doi:10.1136/thorax.57.10.847

6. Viniol C, Vogelmeier CF. Exacerbations of COPD. Eur Respir Rev. 2018;27(147):170103. doi:10.1183/16000617.0103-2017

7. Miravitlles M, García-Polo C, Domenech A, Villegas G, Conget F, de la Roza C. Clinical outcomes and cost analysis of exacerbations in chronic obstructive pulmonary disease. Lung. 2013;191(5):523-530. doi:10.1007/s00408-013-9487-z

8. Dalal AA, Christensen L, Liu F, Riedel AA. Direct costs of chronic obstructive pulmonary disease among managed care patients. Int J Chron Obstruct Pulmon Dis. 2010;5:341-349. doi:10.2147/ COPD.S13771

9. Stafyla E, Geitona M, Kerenidi T, Economou A, Daniil Z, Gourgoulianis KI. The annual direct costs of stable COPD in Greece. Int J Chron Obstruct Pulmon Dis. 2018;13:309-315. doi: $10.2147 /$ COPD.S148051

10. Lisspers K, Larsson K, Johansson G, et al. Economic burden of COPD in a Swedish cohort: the ARCTIC study. Int J Chron Obstruct Pulmon Dis. 2018;13:275-285. doi:10.2147/COPD.S149633

11. Huber MB, Wacker ME, Vogelmeier CF, Leidl R. Excess costs of comorbidities in chronic obstructive pulmonary disease: a systematic review. PLoS One. 2015;10(4):e0123292. doi:10.1371/journal.pone. 0123292

12. Mannino DM, Higuchi K, Yu TC, et al. Economic burden of COPD in the presence of comorbidities. Chest. 2015;148(1):138-150. doi:10.1378/chest.14-2434

13. Gerdtham UG, Andersson LF, Ericsson A, et al. Factors affecting chronic obstructive pulmonary disease (COPD)-related costs: a multivariate analysis of a Swedish COPD cohort. Eur J Health Econ. 2009;10(2):217-226. doi:10.1007/s10198-008-0121-6
14. Li M, Wang F, Chen R, et al. Factors contributing to hospitalization costs for patients with COPD in China: a retrospective analysis of medical record data. Int $J$ Chron Obstruct Pulmon Dis. 2018;13:3349-3357. doi:10.2147/COPD.S175143

15. Chen X, Wang N, Chen Y, Xiao T, Fu C, Xu B. Costs of chronic obstructive pulmonary disease in urban areas of China: a cross-sectional study in four cities. Int J Chron Obstruct Pulmon Dis. 2016;11:2625-2632. doi:10.2147/COPD.S118523

16. Ornek T, Tor M, Altın R, et al. Clinical factors affecting the direct cost of patients hospitalized with acute exacerbation of chronic obstructive pulmonary disease. Int J Med Sci. 2012;9(4):285-290. doi:10.7150/ijms.4039

17. Dal Negro RW, Bonadiman L, Turco P, Tognella S, Iannazzo S. Costs of illness analysis in Italian patients with chronic obstructive pulmonary disease (COPD): an update. Clinicoecon Outcomes Res. 2015;7:153-159. doi:10.2147/CEOR.S77504

18. Chinese Expert Group on the diagnosis and treatment of acute exacerbation of chronic obstructive pulmonary disease (AECOPD). Chinese expert consensus on the diagnosis and treatment of acute exacerbation of chronic obstructive pulmonary disease (AECOPD) (revised edition in 2014). Int J Respir. 2014;34:1-11. Chinese.

19. COPD Group of Chinese Society of Respiratory Disease. Guideline for diagnosis and treatment of chronic obstructive pulmonary disease (revised edition in 2013). Chin J Fron Med Sci. 2013;6(2):67-80. Chinese

20. Jinjuvadia C, Jinjuvadia R, Mandapakala C, Durairajan N, Liangpunsakul S, Soubani AO. Trends in outcomes, financial burden, and mortality for acute exacerbation of chronic obstructive pulmonary disease (COPD) in the United States from 2002 to 2010. COPD. 2017;14(1):72-79. doi:10.1080/15412555.2016.1199669

21. National Center for Health Statistics (NCHS). Diseases of the respiratory system (J00-J99). In: national center for health statistics (NCHS), ed. ICD-10-CM official guidelines for coding and reporting FY 2020. Available from: https://www.cdc.gov/nchs/data/icd/ 10cmguidelines-FY2020_final.pdf. Accessed August 24, 2019.

22. Souliotis K, Kousoulakou H, Hillas G, Tzanakis N, Toumbis M, Vassilakopoulos T. The direct and indirect costs of managing chronic obstructive pulmonary disease in Greece. Int $J$ Chron Obstruct Pulmon Dis. 2017;12:1395-1400. doi:10.2147/COPD.S132825

23. Chen Z. Launch of the health-care reform plan in China. Lancet. 2009;373(9672):1322-1324. doi:10.1016/S0140-6736(09)60753-4

24. Perera PN, Armstrong EP, Sherrill DL, Skrepnek GH. Acute exacerbations of COPD in the United States: inpatient burden and predictors of costs and mortality. COPD. 2012;9(2):131-141. doi:10.3109/ 15412555.2011.650239

25. Deniz S, Sengul A, Aydemir Y, Celdir Emre J, Özhan MH. Clinical factors and comorbidities affecting the cost of hospital-treated COPD. Int J Chron Obstruct Pulmon Dis. 2016;11:3023-3030. doi:10.2147/COPD.S120637

26. Torabipour A, Hakim A, Ahmadi Angali K, Dolatshah M, Yusofzadeh M. Cost analysis of hospitalized patients with chronic obstructive pulmonary disease: a state-level cross-sectional study. Tanaffos. 2016;15(2):75-82.

27. Liu H, Wang N, Chen W, et al. Hospitalization trends in adult patients with COPD and other respiratory diseases in northeast China from 2005 to 2015. Biomed Res Int. 2018;2018:1-7.

28. de Miguel-díez J, Jiménez-García R, Hernández-Barrera V, et al. Trends in hospital admissions for acute exacerbation of COPD in Spain from 2006 to 2010. Respir Med. 2013;107(5):717-723. doi:10.1016/j.rmed.2013.01.007

29. Yip WC, Hsiao WC, Chen W, Hu S, Ma J, Maynard A. Early appraisal of China's huge and complex health-care reforms. Lancet. 2012;379(9818):833-842. doi:10.1016/S0140-6736(11)61880-1 


\section{Publish your work in this journal}

The International Journal of COPD is an international, peer-reviewed journal of therapeutics and pharmacology focusing on concise rapid reporting of clinical studies and reviews in COPD. Special focus is given to the pathophysiological processes underlying the disease, intervention programs, patient focused education, and self management protocols. This journal is indexed on PubMed Central, MedLine and CAS. The manuscript management system is completely online and includes a very quick and fair peer-review system, which is all easy to use. Visit http://www.dovepress.com/testimonials.php to read real quotes from published authors. 